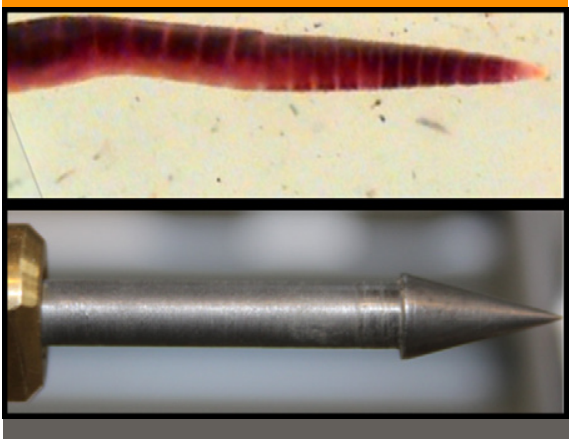

Core Ideas

- Analytic model for penetrationexpansion forces closely agrees with measurements.

- Measurements used cones with size geometry similar to earthworms and roots.

- Soil parameters and constraints for root and earthworm bioturbation are estimated.

- To form new burrows, earthworms need to consume $0.3 \mathrm{~kg} \mathrm{C} \mathrm{m}^{-2} \mathrm{yr}^{-1}$.

S. Ruiz, I. Straub, S.J. Schymanski, and D. Or, Dep. of Environmental Systems Science, ETH Zurich, 8092 Zurich, Switzerland. *Corresponding author (siul.ruiz@usys.ethz.ch).

Vadose Zone J.

doi:10.2136/vzj2015.09.0126

Open access.

Received 11 Sept. 2015.

Accepted 16 Nov. 2015.

(C) Soil Science Society of America 5585 Guilford Rd., Madison, WI 53711 USA. All rights reserved.

\section{Experimental Evaluation of Earthworm and Plant Root Soil Penetration-Cavity Expansion Models Using Cone Penetrometer Analogs}

\author{
Siul Ruiz,* Isabelle Straub, Stanislaus J. Schymanski, \\ and Dani Or
}

Recent mechanical models of soil penetration by earthworms and plant roots based on penetration-cavity expansion were tested using cone penetration measurements at scales compatible with the sizes of earthworms and plant roots. Measurements using different cone radii $(1.0-2.5 \mathrm{~mm})$ and cone semi-apex angles $\left(15-30^{\circ}\right)$ were obtained for a range of soils and water contents at highly resolved penetration forces and constant insertion rates. The cone penetration measurements were interpreted using independently determined soil mechanical parameters and yielded good agreement with predictions from an analytical mechanical model. Experimental confirmation of penetration force predictions supports estimates of energy costs associated with soil bioturbation that vary with soil hydration status and mechanical characteristics. Effects of soil friction and axial compaction were assessed by comparing the results from conventional and recessed cones (to eliminate soil-shaft friction). The study provides new insights into quantitative soil bioturbation processes and expands predictive capabilities of the mechanics and energetics of earthworm activity and root zone dynamics related to soil structure development.

Abbreviations: LEFM, linear elastic fracture mechanics; SOC, soil organic carbon.

Soil penetration and internal volume displacement by growing plant roots and by burrowing earthworms require significant amounts of mechanical energy. Bioturbation processes associated with life in the subsurface play an important role in the formation of soil structure and affect a range of soil physical, hydrological, and ecological functions (Bottinelli et al., 2014; Brown et al., 2000; Watts et al., 1999). For heterotrophic organisms, the mechanical costs of soil penetration are largely constrained by available energy sources needed to support subterranean activities. For example, the amount of (particulate) soil organic $\mathrm{C}$ (SOC) required to support the mechanical bioturbation energy requirements of generic earthworm communities (Lavelle et al., 2007) was estimated to represent up to 5\% of the net primary productivity of croplands per year (Ruiz et al., 2015). These theoretical, mechanically based estimates are within the range of observed soil $\mathrm{C}$ depletion rates by earthworm populations (Alban and Berry, 1994).

Despite the significance of the energy costs of soil bioturbation for subsurface $\mathrm{C}$ storage and for the maintenance of soil structure, the experimental determination of the energetics of soil penetration by earthworms and plant roots remains a challenge. Mechanical analyses of bioturbation have focused on determining radial and axial stresses exerted by earthworms and plant roots necessary to fracture stiff dry soil or chalk (McKenzie and Dexter, 1988; Misra et al., 1986). Such measurements are difficult to perform and are not general for different soil and climatic conditions, biological community structure, and other factors. A surrogate measure based on cone penetrometer resistive forces 
was found to be in good agreement with estimated plant root resistance pressures in soils (Abdalla et al., 1969; Dexter, 1987; Greacen and Oh, 1972) and has been proposed to represent the geometrical and mechanical features resembling earthworm burrowing (Ruiz et al., 2015). In addition to geometric similarities, cone penetrometer measurements are useful for determining various soil mechanical properties due to their simplicity and ability to provide real-time data (Salgado and Prezzi, 2007; Yu, 1993; Yu and Mitchell, 1998). Penetrometer measurements have been used as qualitative indicators of soil structural properties such as soil strength and compaction level (Adamchuk et al., 2004). A few studies have interpreted cone penetration resistance stress as the soil strength itself (Unger and Kaspar, 1994); others have used supplemental measurements by coupling inflatable probes to the penetrometer shaft to deduce soil mechanical properties from rebounding pressures (Houlsby and Withers, 1988). Recent approaches have used empirical correlations to deduce the soil bulk density and soil strength as functions of penetrometer pressure and soil matric potential (Whalley et al., 2007). These mechanical factors are known to influence the rates of root growth and earthworm burrowing activity in soil (Bengough and Mullins, 1990; McKenzie and Dexter, 1988; Misra et al., 1986).

Some of the early experimental attempts to relate miniaturized cone penetration with plant root growth were reported by Stolzy and Barley (1968), who utilized 1.5-mm-radius cones with a semiangle of $30^{\circ}$ to characterize the ratio between probe and root resistance. Their early findings suggested that plant roots experience $<75 \%$ of the penetration forces of a metal cone penetrometer. Bengough et al. (1997) quantified the coefficient of friction for different cone angles, how it changes during rotation, and how it differs from plant roots. However, a rigorous theoretical understanding of soil penetration mechanics was typically derived from geotechnical applications that rely on large penetrometer geometries and thus are not directly compatible with the geometries of earthworms and plant roots.

An early mechanical model for cone penetration of soil was developed by Bishop et al. (1945) based on the concept of an expanding cavity for quantifying pressures required for cone penetration. Cavity expansion models account for both elastic and plastic soil deformation. Yu (1993) and Durban and Fleck (1992) developed semi-empirical relationships that account for angular and interfacial friction effects during modeled penetration. Other modeling approaches to cone penetration were developed based on discrete element and other numerical models (Johnson, 2003).

Ruiz et al. (2015) recently proposed a penetration model that characterizes the radial stresses at the penetrating tip as a function of the cavity radius and used it to estimate the mechanical stresses and energetics related to soil penetration by earthworms and plant roots. A key novelty in this modeling methodology is the dependency of stresses on the cone radius at the scales of earthworms and plant roots. In the present study, we endeavored to test this modeling approach and establish quantitative links between penetration measurements and soil mechanical properties. The specific objectives were to: (i) quantify and explain the relationship between penetration stresses and forces for geometries compatible with earthworms and plant roots; (ii) test the root-earthworm scale penetration theory of Ruiz et al. (2015); (iii) compare current model results with previously used penetration models; (iv) determine how friction affects penetration measurements; and (v) investigate the potential for determining soil mechanical properties from penetrometer measurements.

An analytical model based on cavity expansion processes suitable for small cone radii was presented by Ruiz et al. (2015). We have developed a new, physically based coupling of the frictional influences. We compared our model with the cone penetration measurements and then with the classical limit pressure model (Carter et al., 1986), a model that considers the influence of friction and penetration angles (Yu, 1993), and a linear elastic fracture mechanics (LEFM) model that has been proposed to describe penetration-expansion of marine earthworms (Dorgan et al., 2011). We then investigated the potential for using such measurements to obtain soil mechanical parameters in undisturbed samples and estimated the mechanical energy requirements for bioturbation. We put the findings of the present study into context with the existing literature to highlight the main implications, potential caveats, and need for further research.

\section{Materials and Methods \\ Modeling Penetration-Expansion in Elasto-Plastic Media}

We begin with an equilibrium equation for stresses associated with cylindrical cavity expansion (Carter et al., 1986). The stress around a cylindrical cavity decays with the radius $r$ away from the center of the cavity into the soil:

$\frac{\partial \sigma_{r}}{\partial r}+\frac{\sigma_{r}-\sigma_{\theta}}{r}=0$

where $\sigma_{\mathrm{r}}$ is the radial stress and $\sigma_{\theta}$ is the hoop (circumferential) stress.

Soil plasticity is represented by the Mohr-Coulomb criterion, relating the difference between the radial and hoop stresses to the summation of stresses multiplied by a component of the internal friction and undrained soil strength:

$\sigma_{r}-\sigma_{\theta}=\left(\sigma_{r}+\sigma_{\theta}\right) \sin (\phi)+\left(2 s_{\mathrm{u}}\right) \cos (\phi)$

where $\phi$ is the internal angle of friction and $s_{\mathrm{u}}$ is the undrained soil strength. Following Yu (1993) and Durban and Fleck (1992), we assume frictionless soils, i.e., $\phi=0$, which results in the von Mises yield criterion (von Mises, 1913). We assume that the deformation 
during penetration is plastically dominated, thus we utilize the plastic radial stress distribution to approximate the stresses for smaller cavity sizes, with the stresses becoming singular at the small surface area of the cone tip (Fig. 1).

In the plastic regime, the radial stress can be estimated by substituting Eq. [2] into Eq. [1], yielding the following differential equation (Ruiz et al., 2015):

$$
\frac{\partial \sigma_{r}}{\partial r}=-\frac{2 s_{\mathrm{u}}}{r}
$$

We treat the experimental geometry used by Bishop et al. (1945) as the plastic radial boundary condition due to the cone radius being small and compatible with the limit pressure theory. Thus $\sigma_{r}\left(r_{\mathrm{p}}\right)$ $=P_{\mathrm{L}}$, where $r_{\mathrm{p}}(4.5 \mathrm{~mm})$ is the radius of the cone used by Bishop et al. (1945) and $P_{\mathrm{L}}$ is the limit pressure, given as

$P_{\mathrm{L}}=s_{\mathrm{u}}\left[1+\ln \left(\frac{G}{s_{\mathrm{u}}}\right)\right]$

where $G$ is the shear modulus of rigidity and $s_{\mathrm{u}}$ is the undrained soil strength. Solving the differential Eq. [3] for these boundary conditions gives

$\sigma_{r}(r)=P_{\mathrm{L}}-2 s_{\mathrm{u}} \ln \left(\frac{r}{r_{\mathrm{p}}}\right)$

To map the cylindrical radial stresses in the correct direction to the conical surface, the cone is represented as the summation of many incrementally partitioned cylinders of increasing radius (Fig. 1b).

Each cylindrical surface has an incremental surface area $A_{\mathrm{c} i}$ :

$$
\Delta A_{\mathrm{c} i}=2 \pi r_{i} \Delta z_{i}
$$

where $\Delta z_{i}$ is the incremental cylinder length and $r_{i}$ is the cylinder radius of the $i$ th increment. The cylindrical surface area on which the radial stresses act is then given by

$$
A_{\mathrm{c}}=\lim _{\left|\Delta z_{i}\right| \rightarrow 0} 2 \pi \sum_{i=1}^{n} r_{i} \Delta z_{i}=2 \pi \int_{0}^{r} r \mathrm{~d} z
$$

Given a cone apex semi-angle $\alpha$, the slope of the cone surface can be expressed as

$$
\frac{\mathrm{d} r}{\mathrm{~d} z}=\tan (\alpha) \rightarrow \mathrm{d} z=\cot (\alpha) \mathrm{d} r
$$

Insertion into Eq. [7] gives the effective cylindrical surface area as a function of the cone apex semi-angle:

$$
A_{\mathrm{c}}=2 \pi \cot (\alpha) \int_{0}^{r} r \mathrm{~d} r=\pi r^{2} \cot (\alpha)
$$

This enables linking radial forces $F_{r}$ and radial stresses $\sigma_{r}$ according to
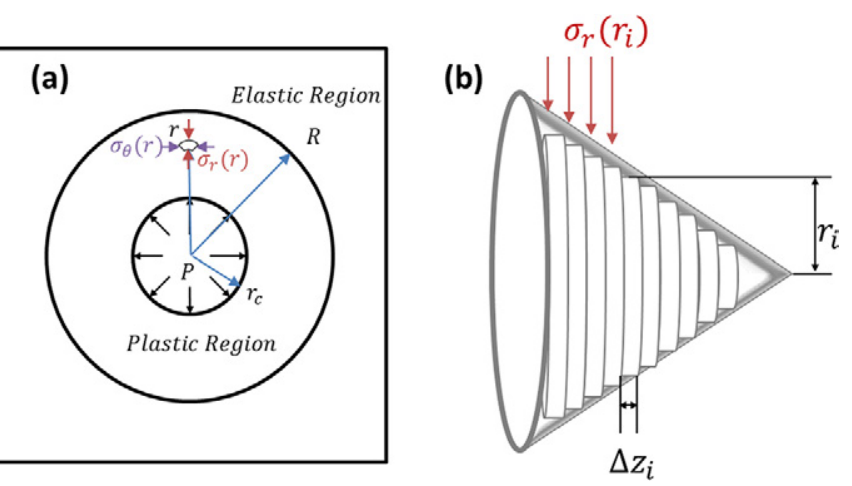

Fig 1. Radial cavity expansive stresses mapped along the radius of the cone face: (a) the cavity expansion model defines a plastic region between an elasto-plastic interface $(R)$ and a cavity $\left(r_{c}\right)$, where outside the material is assumed to deform elastically; (b) the progressively increasing cylindrical cavities are used to properly map the radial stresses along the boundary of a cone partitioned into cylindrical elements.

$F_{r}=\pi r^{2} \cot (\alpha) \sigma_{r}$

where $\alpha$ is the cone apex semi-angle and $r$ is the radius of the submerged section of the cone. The axial force acting on the cone face is then

$$
F_{z}=F_{r} \tan (\alpha)
$$

The radial and axial forces describe frictionless steady-state cone penetration.

\section{Interfacial Friction during Penetration}

To include the effects of interfacial friction between the cone and soil during insertion, an operational expression for forces acting normal to the cone face is needed. The cone normal force is expressed as

$F_{\mathrm{n}}=F_{r} \mathbf{r}+F_{z} \mathbf{z}$

where $\mathbf{r}$ and $\mathbf{z}$ are the unit vectors in the radial and axial directions, respectively.

The frictional forces act in the direction perpendicular to the normal force:

$$
F_{\mathrm{f}}=\mu\left(-F_{z} \mathbf{r}+F_{r} \mathbf{z}\right)
$$

where $\mu$ is the coefficient of friction between the soil and the cone. The sum of all the forces in the axial direction is then expressed as

$$
F_{Z, M}=F_{z}[\mu \cot (\alpha)+1]
$$

This result resembles the classical formulation of Greacen and $\mathrm{Oh}$ (1972), but it illustrates explicitly the frictional influence on the axial forces, while previous formulations expressed the penetration 
resistance as a function of stresses acting normal to the cone face (Bengough and Mullins, 1990). Although the classical formulation is mathematically sound, penetration resistance "measurements" are measured forces converted to stresses. However, for a correct conversion, it is necessary to divide by the cross-sectional area, and it is commonly ignored that the relevant cross-sectional area increases during insertion (Whiteley et al., 1981). The axial stress, or penetrometer resistance stress, $q_{\mathrm{p}}$, can be expressed as

$q_{\mathrm{p}}=\frac{F_{Z, M}}{\pi r^{2}}$

where the radius $r$ is increasing as the cone moves into the soil.

\section{Experimental Procedure: Cone Penetration and Uniaxial Soil Tests}

Custom miniature stainless steel penetrometers were designed to represent realistic geometries of earthworms and plant roots (Fig. 2), with radii of 1 and $2.5 \mathrm{~mm}$ and apex semi-angles of 15 and $30^{\circ}$. The cones were mounted on an Omega LC703-10 load cell that was driven into soil samples using a PERO spindle motor (originally designed as a shear frame, described by Michlmayr et al., 2013). Data were collected with a CR1000 datalogger (Campbell Scientific) at $10-\mathrm{Hz}$ recording frequency. Penetration tests were conducted at a constant rate of $10 \mathrm{~mm} \mathrm{~min}^{-1}$.

Two soil types were used for the cone penetration experiments, a silt loam (Uetliberg) and a loamy sand (Winzler), selected to span a range of soil parameters for model testing (Table 1). Soil and water were mixed to prescribed water contents and were left in sealed plastic containers in an overhead shaker overnight to homogenize the water distribution in the soil sample. Gravimetric soil water content ranged from 15 to $30 \%$ for Uetliberg soil and from 10 to $15 \%$ for Winzler soil.

Before each penetration experiment, the soil was treated with a mortar to destroy aggregates and then packed into a cylinder of $25-\mathrm{mm}$ inner radius and $50-\mathrm{mm}$ height with a centered penetration hole of 2.5-mm diameter (Fig. 3c). The soil cylinder was locked into a 50-mm-long cubic block for better positioning of the cone tip. A plastic cover was placed over the sample to reduce evaporation, and a 1-kg block was placed on the sample to prevent seepage of soil material during penetration (the resulting confining stress was $5 \mathrm{kPa}$ ).

Cone penetration tests were conducted on each sample using the four different cones (combinations of two radii and two apex semi-angles). After each experiment, the soil was removed from the cylinder, mortared, and repacked into the cylinder for a followup experiment (each sample was tested twice for each cone). In summary, each soil type and water content sample was subjected to eight penetration tests (two per cone) for cones of semi-angles 15 and $30^{\circ}$ and base radii of 1.0 and $2.5 \mathrm{~mm}$.

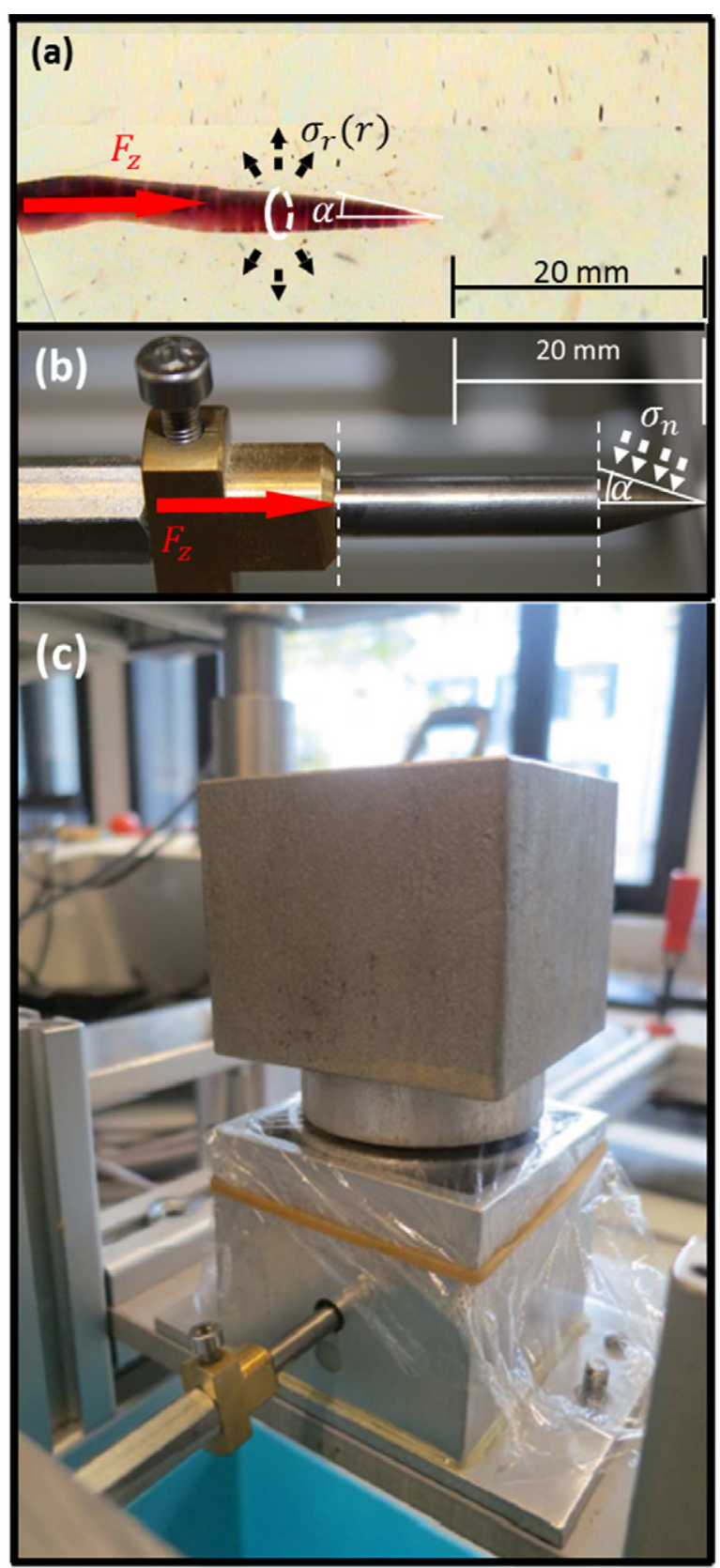

Fig. 2. Representation of an earthworm by a cone penetrometer: (a) geometry during penetration of an earthworm in agar (radius of 2 $\mathrm{mm}$ ); (b) miniature cone penetrometer (radius $2.5 \mathrm{~mm}$ ); and (c) cone penetration test into a soil sample held by an aluminum soil sample holder and overlaid with a load of $1 \mathrm{~kg}$ (same cone as in b).

Each soil sample was subsequently mortared and repacked to conduct an unconfined compression test (Wille Geotechnik PR 10). The unconfined compression tests provided information on the soil modulus of elasticity and yield strength. Several load and unload cycles were performed to determine soil elastic properties (Berli et al., 2006). During these loading-unloading cycles, Young's modulus $E$ was calculated as

$E=\frac{\Delta \sigma}{\Delta \varepsilon}$ 
Table 1. Soil textural properties and van Genuchten water retention parameters, where $\theta_{s}$ is the saturated water content, $\theta_{r}$ is the residual water content, and $\alpha_{\mathrm{v}}$ and $n_{\mathrm{v}}$ are shape parameters.

\begin{tabular}{|c|c|c|c|c|c|c|c|}
\hline Soil & Clay & Silt & Sand & $\alpha_{\mathrm{v}}$ & $n_{\mathrm{v}}$ & $\theta_{s}$ & $\theta_{\mathrm{r}}$ \\
\hline & \multicolumn{3}{|c|}{$-\%(\mathrm{w} / \mathrm{w})$} & \multicolumn{2}{|l|}{$\mathrm{m}^{-1}$} & \multicolumn{2}{|c|}{$-\mathrm{m}^{3} \mathrm{~m}^{-3}-$} \\
\hline Uetliberg (silt loam) & 11 & 50 & 39 & 0.52 & 1.50 & 0.58 & 0.15 \\
\hline Winzler (loamy sand) & 9 & 9 & 82 & 6.67 & 1.64 & 0.48 & 0.06 \\
\hline
\end{tabular}

where $\Delta \sigma$ is the change in the vertical stress within the elastic unloading branch and $\Delta \varepsilon$ is the change in the vertical strain within the elastic regime (predetermined as the maximum stress in the previous load step). Load-unload cycles were conducted until the stress-strain curve flattened at some stress value $\left(\sigma_{\mathrm{y}}\right)$, which was then used to estimate the soil shear strength $\left(s_{\mathrm{u}}\right)$ based on the von Mises law (Durban and Fleck, 1992):

$s_{\mathrm{u}}=\frac{\sigma_{\mathrm{y}}}{\sqrt{3}}$

The sample was again mortared and repacked for a final confined uniaxial compression test. The confined compression test was used to determine the Poisson's ratio of the soil (the ratio of transverse to axial strains). The confined tests also used load-unload cycles to construct a mechanical regime where the soil behaves elastically. By confining the transverse strains and determining Young's modulus from the unconfined test, Poisson's ratio was determined based on the formulation given by Eggers et al. (2006), using the stress-strain relationship:

$\sigma_{i i}=\frac{E}{(1+\nu)(1-2 \nu)}\left[\nu\left(\varepsilon_{j j}+\varepsilon_{k k}\right)+(1-\nu) \varepsilon_{i i}\right]$

where $\sigma_{i i}$ is a normal stress acting in the $i$ th direction, $\varepsilon_{i i}$ is a normal strain acting in the $i$ th direction, $\varepsilon_{j j}$ is a normal strain acting in the $j$ th direction, and $\varepsilon_{k k}$ is a normal strain acting in the $k$ th direction. The confined compression test allows only normal strains in the axial direction $(z)$, thus the relationship becomes

$\sigma_{z}=\frac{E}{(1+\nu)(1-2 \nu)}\left[(1-\nu) \varepsilon_{z}\right]$

Poisson's ratio is then obtained from (Eggers et al., 2006)

$\nu=\frac{1}{4}\left[\frac{\Delta \varepsilon_{z}}{\Delta \sigma_{z}} E \pm \sqrt{\left(1-\frac{\Delta \varepsilon_{z}}{\Delta \sigma_{z}} E\right)\left(9-\frac{\Delta \varepsilon_{z}}{\Delta \sigma_{z}} E\right)}-1\right]$

where $E(\mathrm{~Pa})$ is Young's modulus determined from the unconfined experiment, $\Delta \varepsilon_{z}\left(\mathrm{~m} \mathrm{~m}^{-1}\right)$ is the change in the axial strain within the elastic regime, and $\Delta \sigma_{z}(\mathrm{~Pa})$ is the change in the axial stress within the elastic regime. Because none of the soil samples tested behaved as an auxetic material, only positive values for Poisson's ratio were considered.

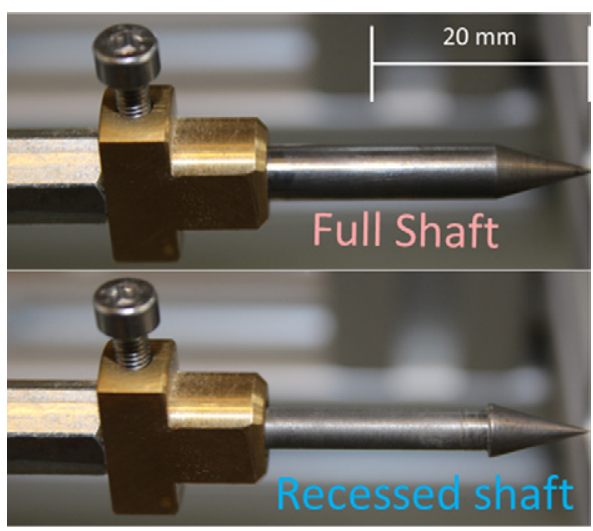

Fig. 3. The continuous-shaft cone (top) vs. recessed-shaft cone (bottom). Radius of the cone base is $2.5 \mathrm{~mm}$, and the semi-angle in the figure is $15^{\circ}$. The recessed shaft radius is $1.9 \mathrm{~mm}$. Cones with a $30^{\circ}$ semi-angle were also tested.

The cone penetration model considers radial cavity expansion and requires the soil shear modulus, which was deduced from Young's modulus and Poisson's ratio as

$G=\frac{E}{2(1+v)}$

The soil mechanical parameters determined from uniaxial experiments were used as input for the penetration-expansion model (Table 2).

The soil mechanical parameters used in this study were determined for fixed saturation values and assuming that variations in saturation would affect the soil strength. At the clay platelets scale, higher saturation lubricates and increases mobility, as well as facilitating the reorientation of clay particles (Mitchell and Soga, 2005). At the sample scale, these changes are manifested by lower yield stress and shear strength (Ghezzehei and Or, 2001). In granular soils, increasing water content reduces the soil suction-induced stresses (Lu et al., 2010) and lowers soil strength. Hallett et al. (2014) have shown evidence for a simple relationship between pore water pressure and yield stress:

$\sigma_{\mathrm{y}}=\frac{2 \gamma}{r_{\mathrm{p}}}$

Table 2. Soil mechanical parameters determined from compression tests (uniaxial cell) and used for cone penetration modeling.

\begin{tabular}{|llllll|}
\hline Soil & Water content & Shear modulus & Poisson's ratio & Soil strength \\
\hline \multirow{4}{*}{ Uetliberg } & $\mathrm{kg} \mathrm{kg}^{-1}$ & $\mathrm{kPa}$ & $\mathrm{m} \mathrm{m}^{-1}$ & $\mathrm{kPa}$ \\
& 15 & 4615 & 0.30 & 69.3 \\
& 20 & 3401 & 0.47 & 86.6 \\
& 30 & 833 & 0.49 & 28.9 \\
Winzler & 10 & 1333 & 0.49 & 14.4 \\
& 12 & 1000 & 0.48 & 17.3 \\
& 15 & 666 & 0.49 & 17.3 \\
\hline
\end{tabular}


where $\sigma_{\mathrm{y}}$ is the soil yield stress, $\gamma$ is the surface tension of water $\left(0.072 \mathrm{~N} \mathrm{~m}^{-1}\right)$, and $r_{\mathrm{p}}$ is the radial pore size of the soil.

\section{Cavity-Expansion Model Evaluation and Intercomparison}

The model of Ruiz et al. (2015) was compared with classical limit pressure models (Carter et al., 1986) and with penetration-expansion models that consider the influence of friction and penetration angles (Yu, 1993). Although fracture mechanical parameters were not directly measured in this study, the LEFM model parameters were determined using the material correlations of Wang et al. (2007):

$K_{\mathrm{IC}, \mathrm{EP}}=\beta \sigma_{\mathrm{y}}$

where $K_{\mathrm{IC}, \mathrm{EP}}$ is the elasto-plastic fracture toughness, $\sigma_{\mathrm{y}}$ is the yield stress, and $\beta$ is a proportionality coefficient (assumed by Wang et al. [2007] to be 0.355). Due to the soil plastic deformation, a relationship between elasto-plastic fracture mechanics and LEFM parameters was also considered (Yoshida and Hallett, 2008):

$K_{\mathrm{IC}, \mathrm{LE}}=\frac{3}{2} K_{\mathrm{IC}, \mathrm{EP}}$

where $K_{\mathrm{IC}, \mathrm{LE}}$ is the linear elastic fracture toughness. These were used to compare our model with the LEFM model proposed for sediment penetration by marine worms (Dorgan et al., 2011).

\section{Influence of Shaft Friction}

A common concern when comparing cone penetrometer results with plant root or earthworm penetration are the potential effects of friction. Bengough et al. (1997) estimated the coefficient of friction between metal cone penetrometers and soil on the order of $\mu=0.55$. Earthworms and plant roots are known to exude biopolymers for reducing friction (among other functions) such as earthworm mucus (Gray and Lissmann, 1938) and plant root mucilage (Kroener et al., 2014). For plant roots, frictional effects are likely to be further reduced due to their tip-wise growth, where roots extend by producing new tissue behind the advancing tip while the main root "shaft" remains anchored within the soil and thus experiences no frictional effects.

Standard cone penetrometers gradually increase the soil contact area with their cone during initial penetration and then with their shaft as soil rebounds behind the tip. The result is enhancement of the frictional effects after the cone is fully inserted in proportion to the inserted shaft length. We assume that the normal force per area on the shaft is constant, i.e., that the normal forces acting on the shaft are linearly proportional to the increasing surface area past the cone base:

$F_{\mathrm{n}, \mathrm{s}} \propto A_{\mathrm{s}, \mathrm{s}}$

where $F_{\mathrm{n}, \mathrm{s}}$ is the normal force acting on the penetrometer shaft and $A_{s, s}$ is the cylindrical surface area of the shaft after the cone base, given as
$A_{\mathrm{s}, \mathrm{s}}=2 \pi r\left(z-l_{\mathrm{c}}\right)$

where $r$ is the shaft radius, $l_{\mathrm{c}}$ is the cone length, and $z$ is the length of the shaft section in contact with the soil. The normal force acting on the shaft depends on soil rebound after passage of the cone. Houlsby and Withers (1988) measured and quantified the radial rebounding pressures by fitting an inflatable probe to the shaft of a penetrometer, which resulted in normal forces acting on the shaft:

$F_{\mathrm{n}, \mathrm{s}}=2 s_{\mathrm{u}} A_{\mathrm{s}, \mathrm{s}}$

where $2 s_{\mathrm{u}}$ is the expression for the plastic unloading pressures acting on the cylindrical surface (Houlsby and Withers, 1988). The resulting frictional forces are

$\left\|F_{\mathrm{f}, \mathrm{s}}\right\|=\mu\left\|F_{\mathrm{n}, \mathrm{s}}\right\|$

where $\mu(=0.55$ [dimensionless] $)$ is the interfacial friction coefficient between the soil and metal, and $F_{\mathrm{f}, \mathrm{s}}$ is the frictional force acting in the axial direction. To isolate this frictional effect, we designed cones with recessed shafts, otherwise identical to the original cones (Fig. 3). The shafts were recessed to a $1.9-\mathrm{mm}$ radius.

\section{Characterizing Axial Soil Deformation}

To better characterize the influence that the cone semi-angle has on axial soil deformation, we performed a finite-elements simulation. We conducted a detailed finite-element analysis using COMSOL 4.3b (COMSOL, 2012) to visualize the affected soil domain around the different cones. We considered axial-symmetric conditions and assumed a frictionless soil-cone interface. To mitigate the geometric complexities and changes in nodal contacts, only small perturbations (0.5-mm insertion) were considered. An adaptive mesh refinement algorithm was implemented to obtain better resolution (Tolooiyan and Gavin, 2011).

\section{Inverse Determination of Soil Mechanical Properties from Cone Penetration Measurements}

Typical soil mechanical properties are often determined at scales much larger than the millimeter scales experienced by earthworms and plant roots penetrating soil. To determine mechanical parameters at a scale compatible with soil penetration by earthworms and roots, we investigated the possibility of determining the parameters inversely by fitting model predictions to measured penetrometer data. We used cone penetration measurements for the 15 and $30^{\circ}$ apex semi-angles and $2.5-\mathrm{mm}$ cone base radius. To avoid shaft frictional effects, we considered penetration forces up to full cone insertion only. For each cone geometry, we applied a nonlinear least squares procedure between the data and the model as described by Wraith and Or (1998) and implemented with Microsoft Excel. To fit the model, we adjust the soil strength $s_{\mathrm{u}}$ and shear modulus $G$. Initial values for $G$ and $s_{\mathrm{u}}$ were estimated as 1667 and $5.8 \mathrm{kPa}$, respectively. The inverse procedure was applied as follows: 
1. We first defined a sequence of measured data $\left\{\left(x_{i}, y_{i}\right), i=1, \ldots\right.$, $N\}$, where $y_{i}=F_{Z, M i}$ is the measured penetration force, and associated depth (distance) $x_{i}=z_{i}$.

2. We converted the measured axial force $\left(y_{i}=F_{Z, M i}\right)$ to estimate the penetration-resistant stress $\left(y_{i}{ }^{*}=q_{\mathrm{p} i}\right.$ using Eq. [15]) and penetration depths to penetrometer radius $\left(x_{i}{ }^{*}=r_{i}\right.$ using Eq. $[8])$.

3. We defined a parameter space $\left\{a_{i}, i=1, \ldots, M\right\}=\left\{G, s_{\mathrm{u}}\right\}$, where $G$ is the shear modulus and $s_{\mathrm{u}}$ is the shear strength.

4. We defined a function of the independent variable and parameters $f\left(x_{i}^{*}, a_{i}\right)=\sigma_{\mathrm{r}}\left(r_{i}, G, s_{\mathrm{u}}\right)$.

5. Assuming a fixed interfacial friction value of $\mu=0.55$ and a fixed semi-apex angle $\alpha$, we converted the theoretical radial stress $f\left(x_{i}{ }^{*}, a_{i}\right)=\sigma_{\mathrm{r}}$ to an axial penetration-resistant stress $f$ $*\left(x_{i}^{*}, a_{i}\right)=q_{\mathrm{p}}$ (using Eq. [10], [11], [14], and [15]).

6. We then defined a cost function as

$$
\chi^{2}(a)=\sum_{i=1}^{N}\left[y_{i}{ }^{*}-f^{*}\left(x_{i}, G, s_{\mathrm{u}}\right)\right]^{2}
$$

7. The process adjusts soil strength $s_{\mathrm{u}}$ and $G$ to minimize $\chi$.

For cone designs with obtuse angles, in addition to cavity expansion stresses, a certain compression ahead of the cone may add a component not accounted for by the model to the insertion force. Consequently, we expect model predictions based on cavity expansion only to underestimate the actual (observed) forces required for soil penetration.

\section{Results}

\section{Comparison of Measured and Predicted Cone Penetration Forces and Stresses}

For cones with the same apex semi-angle but different base diameters, we expect resistive forces (and stresses) to coincide up to the point of full insertion of the smallest cone because the geometry of the uninserted part of the cone plays no role in the mechanical behavior of the inserted part. Penetration impedance (resistive force) is commonly reported in terms of either stress or force, with the conversion from force to stress based on dividing force by the cross-sectional area of the cone base (Whalley et al., 2005). For a given cone geometry, insertion forces were initially independent of the cone base radius until a certain (geometrically determined) insertion depth. This suggests that division of the forces by the cone base crosssectional area would result in stresses that do not coincide for cones with the same apex semi-angles but different diameters. However, division of the measured penetration forces by the cross-sectional area of the inserted part of the cone resulted in stresses showing consistent overlap up to the point of full cone tip insertion (as expected). In other words, the proper conversion of insertion forces to applied stresses must consider the immediately submerged cross-section and not the base cross-section. This result illustrates a seemingly unintuitive trade-off between penetration forces and penetration stresses.

\section{Comparison of Measured and Predicted Cone Penetration Forces}

With increasing penetration depth and cavity radius, the penetration axial force gradually increases while the average stress decreases (Fig. 4). This method for model evaluation was subsequently conducted for the two different soil types (silt loam in Fig. 5 and loamy sand in Fig. 6) under different saturation conditions, cone angles, and cone base radii. Up to full insertion of the cone, the modeled forces are in good agreement with the measured forces. Following the full insertion of the cone, the modeled forces reach a plateau while the measured penetration forces change slope and keep increasing at a nearly constant rate (Fig. 5 and 6), presumably due to shaft friction. Model estimates that consider shaft friction (Eq. [28]) were in good agreement with observations for the sharp $\left(15^{\circ}\right)$ cones, while the model underestimated forces for the blunt cones $\left(30^{\circ}\right)$.

Most measurements showed remarkable agreement with model predictions (also after full cone insertion when shaft friction was considered) in both soil types. Penetration measurements in the loamy sand expressed larger standard deviations than those in the silt loam (Fig. 6). Clear deviations between modeled and measured penetration forces were apparent only for the acute cones $\left(15^{\circ}\right)$ in the loamy sand at intermediate wetness (Fig. 6c) and for the blunt cones $\left(30^{\circ}\right)$ in the silt loam at the wettest condition (Fig. 5f), as well as in the loamy sand at the driest and
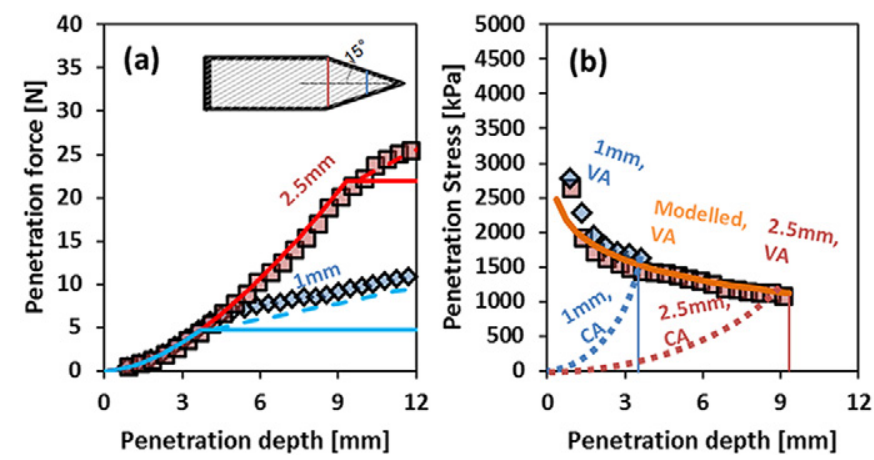

Fig. 4. Measured and modeled (a) insertion (axial) forces and (b) interpreted insertion stresses for 1 - and $2.5-\mathrm{mm}$ base radius cones with a semi-angle of $15^{\circ}$ penetrating silt loam at a water content of $0.15 \mathrm{~kg}$ $\mathrm{kg}^{-1}$. Panel (a) shows modeled forces reaching a plateau at the depth of full cone insertion, whereas measurements demonstrate effects of friction on the cone shaft. Dashed lines in (a) illustrate model results when considering frictional effects using Eq. [28]. Solid orange curve in (b) illustrates model results using Eq. [5], where the radius continuously increases with insertion depth, whereas the dotted lines illustrate division by the fixed cross-sectional base area (variable and constant area denoted with VA and CA, respectively). Each set of data points represents a mean of four separate penetration experiments for the given conditions. 

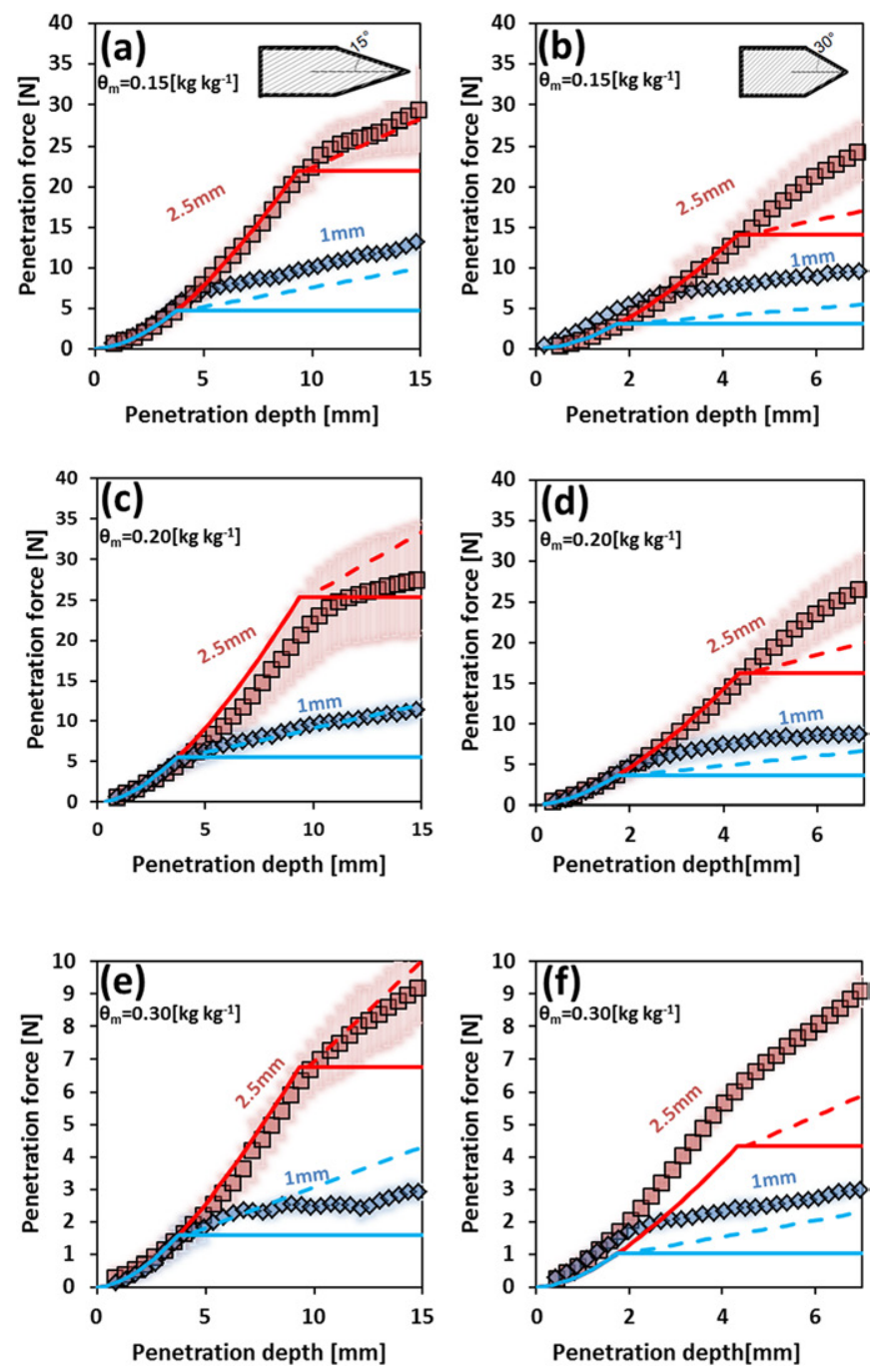

Fig. 5. Penetration force vs. penetration depth for two apex semi-angles $\left(15\right.$ and $\left.30^{\circ}\right)$, shaft diameters ( 1 and $2.5 \mathrm{~mm}$ ), and three water contents $\left(\theta_{\mathrm{m}}\right)$ for silt loam (note that the cone shaft was not recessed as seen in Fig. 3 top). The cone semi-apex angle is located at the top right of the column, water contents are indicated in the top left corner of each panel, and radius is listed next to the results (lines for model predictions and symbols for measurements). The dashed lines indicate the onset of modeled shaft friction after full cone submergence ( 3.7 and $9.3 \mathrm{~mm}$ for a $15^{\circ}$ semi-angle and 1.7 and $4.3 \mathrm{~mm}$ for a $30^{\circ}$ semi-angle). Each data point (symbol) represents an average of four separate penetration experiments for the given conditions (48 experiments in total). Shaded regions denote standard deviations from the mean values.

wettest conditions (Fig. 6b and 6f, respectively). In these cases, penetration forces were underestimated by the model for both penetrometer diameters.

The influence of shaft friction after full cone insertion was captured in most of the acute $\left(15^{\circ}\right)$ cone experiments but not for the blunt cone $\left(30^{\circ}\right)$ design. Despite consideration of shaft friction, the model underestimated the increasing forces after full cone insertion. This indicates the influence of additional factors on penetration forces for blunt cones that were not considered in our model, which are discussed below.
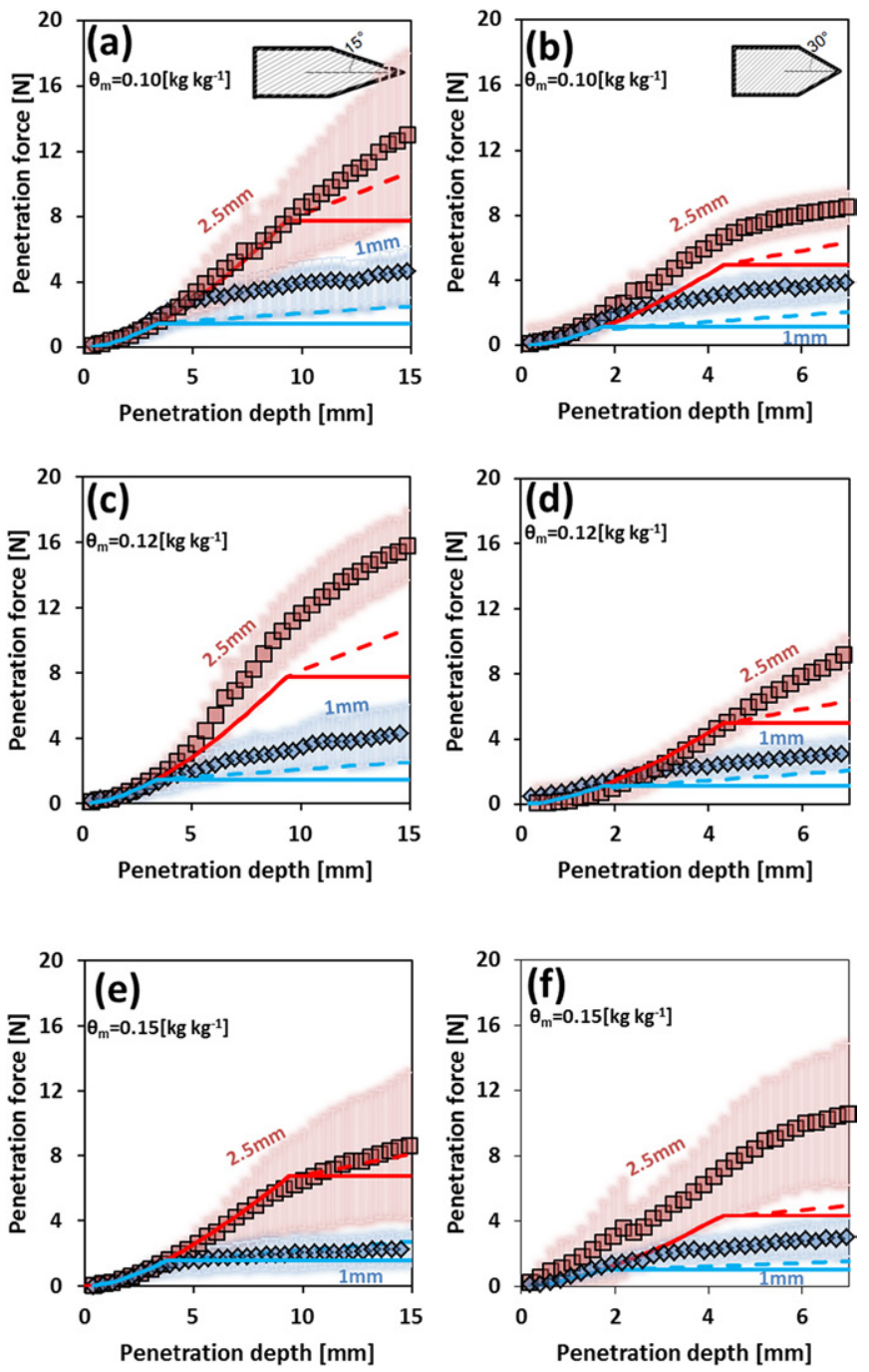

Fig. 6. Penetration force vs. penetration depth for different semi-apex angles, shaft diameters, and water contents for loamy sand. Cone semiapex angle is located at the top right of the column, water contents $\left(\theta_{\mathrm{m}}\right)$ are indicated in the top left corner of each panel, and radius is listed next to the results (lines for model predictions and symbols for measurements). The dashed lines indicate the onset of modeled shaft friction after full cone submergence ( 3.7 and $9.3 \mathrm{~mm}$ for a $15^{\circ}$ semi-angle and 1.7 and $4.3 \mathrm{~mm}$ for a $30^{\circ}$ semi-angle). Each set of data points represents a mean of four separate penetration experiments for the given conditions ( 48 experiments in total). Shaded regions denote standard deviations from the mean values.

\section{Penetration-Cavity-Expansion Model Intercomparison}

Cone penetration force predictions by the model of Ruiz et al. (2015) represented by Eq. [14] were compared with estimates by alternative models for similar cone geometry and compatible soil mechanical parameters (Fig. 7). This model inter-comparison considered both wet $\left(0.15 \mathrm{~kg} \mathrm{~kg}^{-1}\right)$ and dry $\left(0.30 \mathrm{~kg} \mathrm{~kg}^{-1}\right)$ silt loam soil. The results suggest that the simple limit pressure theory predictions of Carter et al. (1986) significantly underestimated cone penetration forces for both wetness conditions. The cone penetration model of $\mathrm{Yu}$ (1993), which uses semi-empirical factors to account for penetration angle and interfacial friction, also 
underestimated measured insertion forces but came much closer to observations than the Carter et al. (1986) model.

In contrast, predictions by the LEFM model (Dorgan et al., 2011; Ruiz et al., 2015) overestimated the measured penetration forces very strongly in the wet soil and less pronounced in the dry soil (Fig. 7). The LEFM also predicted a linear increase in penetration force with penetration depth, while the data and all other models expressed an increasing slope with penetration depth. The models of Yu (1993) and Carter et al. (1986) scaled in a similar way with changes in soil wetness as our experimental data. The model by Ruiz et al. (2015) was the only one that accurately reproduced the observed penetration forces up to full cone insertion, including a nonlinear increase with penetration depth and the correct scaling with soil moisture.

\section{Comparison between Full and Recessed Penetrometer Shafts}

Experiments using the Uetliberg (silt loam) soil were conducted to determine the effects of the recessed cone shaft (Fig. 8) on the measured frictional interactions after full cone insertion. For the acute cone $\left(15^{\circ}\right.$ semi-angle) with recessed shaft, the measurement results in Fig. 8a imply that the insertion force becomes nearly constant after full insertion of the cone tip. This result stands in stark contrast to measurements with a standard (continuous) shaft, which often exhibit a gradual increase in penetration force due to soil-shaft frictional interactions. Results for the $30^{\circ}$ cone semi-angle depicted in Fig. $8 \mathrm{~b}$ did not show a clear difference between the recessed-shaft cones and the standard cones. In both cases, penetration forces continued to rise well after the cone tip was fully inserted into the soil, possibly suggesting that radial strains due to soil rebound were larger than the extent of the recession $(0.6 \mathrm{~mm})$.

\section{Characterizing Axial Soil Deformation at the Cone Tip}

Relative to observations, the analytic model performed best for the cones with an acute angle $\left(15^{\circ}\right)$, but predictions deteriorated for blunt cone angles $\left(30^{\circ}\right)$ (Fig. 8). To better understand the differences in stress distribution in the soil related to different cone apex semi-angles, we performed COMSOL finite-element analyses for two different cone shapes in an elastic-plastic soil (Fig. 9).

The stress distribution ahead of the cone with an obtuse angle $\left(30^{\circ}\right)$ shown in Fig. 9a is nearly spherical, with the yield zone extending nearly $2 \mathrm{~mm}$ ahead of the cone tip. We interpreted the pattern as indicative of large axial compressive stresses relative to those exerted by the acute $\left(15^{\circ}\right)$ cone (Fig. $9 \mathrm{~b}$ ). For the $15^{\circ}$ cone, the yield zone remained close to the cone face, with negligible yielding ahead of the cone tip, suggesting that most of the deformation lay on the outer boundary of the cone face rather than the cone forefront (in agreement with the cavity expansion model assumptions).

\section{Inverse Determination of Soil Mechanical Parameters from Cone Penetration}

Soil mechanical parameters inferred from inversion of the cone penetration measurements for the Uetliberg and Winzler soils (for two cone angles and a range of water contents) are summarized in 


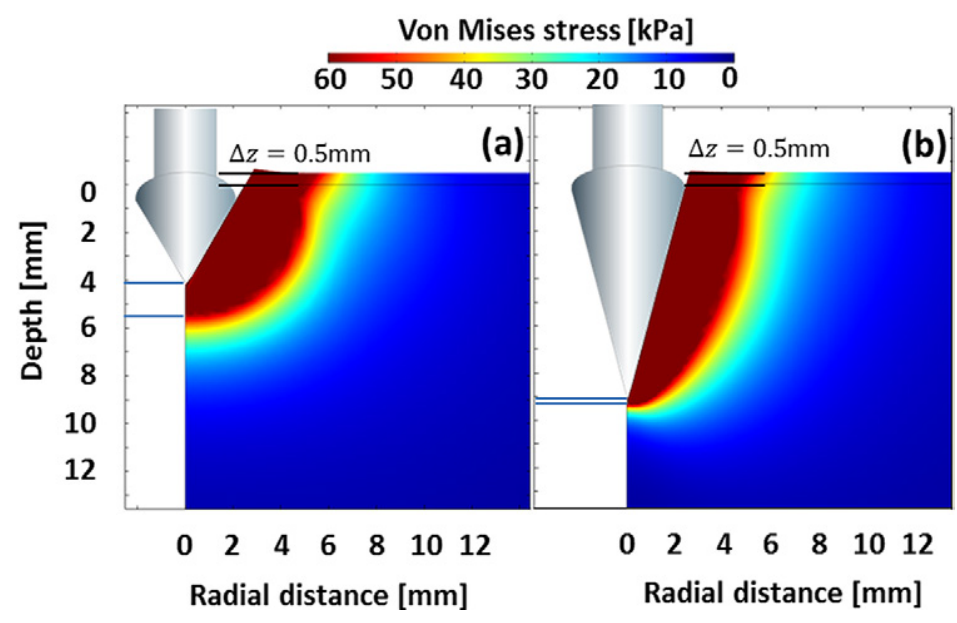

Fig. 9. Finite-element simulation of yield zones during cone tip penetration into an elastic-plastic soil (COMSOL, 2012). Models were designed with an automatic mesh refinement algorithm to adjust for the similarity point at the cone tip. The base radius of both cones was $2.5 \mathrm{~mm}$ and their apex semi-angles were (a) $30^{\circ}$ and (b) $15^{\circ}$. The simulated displacement is 0.5 $\mathrm{mm}$ for both cases. The yield zones (represented in dark red) represent affected regions where stresses in the soil exceed its yield stress, resulting in deformation and compaction by cone insertion. The mechanical parameters used for the calculations are those of the silt loam soil at $0.15 \mathrm{~kg} \mathrm{~kg}^{-1}$ water content presented in Table 1 .

Table 3 (eight replicates per water content). The cone-based soil mechanical parameters were in a similar range to those obtained from uniaxial tests with some notable differences. The values of soil strength $\left(s_{\mathrm{u}}\right)$ deduced from the acute penetrometer measurements were slightly lower than values measured in the uniaxial tests for the Uetliberg soil and higher for the Winzler soil. However, the general trends in soil parameters with water content were in reasonable agreement. The acute penetrometer-determined shear modulus values $(G)$ were similar to values determined from the uniaxial test for the Uetliberg soil and nearly double the values measured by uniaxial tests for the Winzler soil.

The soil mechanical parameters deduced from the obtuse cone $\left(30^{\circ}\right)$ were less consistent with uniaxial test values, especially for the Winzler soil. Comparison of insertion forces for an obtuse semi-angle of $30^{\circ}$ have shown that the measured force was larger by $30 \%$ than that predicted from cavity expansion (for known soil parameters). We could apply a correction factor to the computed $f^{*}$ to account for force components that do not contribute to cavity expansion (Carter et al., 1986). Such corrections would require more systematic studies to evaluate different cone angles and radii; hence, for purposes of this study, we limited the applicability of the inversion method to acute cones $\left(15^{\circ}\right)$. The inversion procedure serves as "proof of concept" pending additional tests to evaluate the consistency of trends and to establish correspondence between soil mechanical parameters derived from cone and uniaxial tests.

\section{Cone Resistance and Energy Requirements for Burrowing in Soil: Ecological Considerations}

The physical model for cone penetration forces can be used to estimate the mechanical energy required for soil penetration by a cone, and by analogy, for creation of a biopore by an earthworm or root growing into the soil. We have used measurements for the $2.5-\mathrm{mm}$ radius cone (similar to the average earthworm radius [Ehlers, 1975]) and to compute the energy per unit length of a burrow for different water contents and soil types. In the results depicted in Fig. 10, we did not consider interfacial frictional effects and converted the energy requirement for burrowing to the equivalent $\mathrm{SOC}$ that would be consumed by hypothetical earthworms. The conversion factor of $0.0484 \mathrm{~g} \mathrm{C} \mathrm{J}^{-1}$ was proposed by Lavelle et al. (2007) and used by Ruiz et al. (2015) to estimate SOC requirements for soil penetration by earthworms. Lastly, the inferred energy calculations were limited to biophysical constraints of the maximum earthworm pressure. Keudel and Schrader (1999) reported that earthworms have a biophysical pressure threshold of $250 \mathrm{kPa}$. Considering an average radius of $2.5 \mathrm{~mm}$, this would amount to mechanical energy (neglecting interfacial friction) for a 1-m length of (250 $\left.\times 10^{3} \mathrm{~Pa}\right) \times \pi \times\left(2.5 \times 10^{-3} \mathrm{~m}\right)^{2} \times 1 \mathrm{~m} \approx 5 \mathrm{~J}$, and converting this to grams of $\mathrm{C}$ would result in $5 \mathrm{~J} \times 0.0484 \mathrm{~g} \mathrm{~J}^{-1} \approx 0.24 \mathrm{~g} \mathrm{C}$ for a 1-m-length burrow (Fig. 10).
Table 3. Soil mechanical parameters (soil strength $s_{\mathrm{u}}$ and shear modulus $G$ ) determined from uniaxial tests and from cone penetrometer inversion.

\begin{tabular}{|c|c|c|c|c|c|c|c|}
\hline \multirow[b]{2}{*}{ Soil } & \multirow{2}{*}{$\begin{array}{l}\text { Water } \\
\text { content }\end{array}$} & \multicolumn{2}{|l|}{ Uniaxial } & \multicolumn{2}{|c|}{ Penetrometer $\left(\alpha=15^{\circ}\right)$} & \multicolumn{2}{|c|}{ Penetrometer $\left(\alpha=30^{\circ}\right)$} \\
\hline & & G & $s_{\mathrm{u}}$ & G & $s_{\mathrm{u}}$ & G & $s_{\mathrm{u}}$ \\
\hline \multirow{3}{*}{ Uetliberg } & $\mathrm{kg} \mathrm{kg}^{-1}$ & $\mathrm{kPa}$ & $\mathrm{kPa}$ & $\mathrm{kPa}$ & $\mathrm{kPa}$ & $\mathrm{kPa}$ & $\mathrm{kPa}$ \\
\hline & 15 & $4615 \pm 600 \dagger$ & $69.3 \pm 10$ & 3543 & 60.3 & 1667 & 78.2 \\
\hline & 20 & $3401 \pm 800$ & $86.6 \pm 9$ & 3565 & 61.2 & 3522 & 60.2 \\
\hline \multirow{4}{*}{ Winzler } & 30 & $833 \pm 300$ & $28.9 \pm 6$ & 2119 & 18.7 & 3628 & 61.9 \\
\hline & 10 & $1333 \pm 41$ & $14.4 \pm 7$ & 2184 & 22.2 & 1667 & 43.2 \\
\hline & 12 & $1000 \pm 52$ & $17.3 \pm 4$ & 2350 & 26.2 & 4256 & 80.0 \\
\hline & 15 & $666 \pm 38$ & $17.3 \pm 6$ & 2078 & 17.6 & 3283 & 52.5 \\
\hline
\end{tabular}

A range of consumed SOC estimates for the mechanical activity of earthworm communities were derived for a range of observed ecological parameters (Table 4). Considering an earthworm population density in an agricultural field of 100 individuals $\mathrm{m}^{-2}$ (observed in the top $20 \mathrm{~cm}$ [Chan, 2001]) and assuming that an individual earthworm is capable of burrowing $15 \mathrm{~m} \mathrm{yr}^{-1}$ on average $\left(0.125 \mathrm{~m} \mathrm{~d}^{-1}\right.$ [Capowiez and Belzunces, 2001; Ligthart and Peek, 1997] during five to eight active months per year [Edwards and Bohlen, 1996]) and factoring, we estimate that an earthworm community burrowing through a soil with a saturation degree of $60 \%$ (where an individual requires $0.2 \times 10^{-3} \mathrm{~kg} \mathrm{C}$ 
$\mathrm{m}^{-1}$ burrow) would consume $0.3 \mathrm{~kg} \mathrm{C} \mathrm{m}^{-2}$ per year just to cover its mechanical energy expenditure $\left(0.2 \times 10^{-3} \mathrm{~kg} \mathrm{C} \mathrm{m}^{-1} \times 15 \mathrm{~m} \mathrm{yr}^{-1} \times\right.$ 100 individuals $\left.\mathrm{m}^{-2} \approx 0.3 \mathrm{~kg} \mathrm{C} \mathrm{m}^{-2} \mathrm{yr}^{-1}\right)$. The typically larger earthworm population densities observed in temperate climates (Bastardie et al., 2005; Lavelle, 1988) and considering drier soils (at field capacity) would raise this estimate by a factor of 10 .

\section{Discussion}

We found general agreement between experimental cone-penetration forces and model predictions based on independently obtained soil mechanical parameters (in particular for sharp $15^{\circ}$ cones). These results inspire confidence in our understanding of the mechanical (and energetic) characteristics of bioturbation by earthworms and roots provided that their soil penetration mode is mechanically analogous (this remains an untested hypothesis). The simple and analytic cone penetration-cavity expansion model performed better in the silt loam soil due to continuum-like behavior relative to the coarser loamy sand with large grains (Winzler). Soil sand particles may rearrange and jam during deformation, violating the continuum assumptions in the model and affecting the resulting force measurements with small cones. In this context, it is interesting to note that earthworms predominantly inhabit light and medium loam soils rather than sandy soils (Booth et al., 2000), which could be either due to more suitable soil mechanical properties or because finer textured soils contain more SOC $(10 \mathrm{~g}$ clay $\approx 1 \mathrm{~g}$ organic $\mathrm{C}$ [Dexter et al., 2008]). Earthworm communities are also sensitive to soil drying (Holmstrup, 2001), hence the characteristics of drying in loamy soils would support a wider window of earthworm activity relative to rapidly drying sandy soils (Curry, 1998).

Comparison of the model presented here with previously proposed models (Fig. 7) highlights the need to consider tip geometry for modeling cone penetration. Conventional cavity expansion models often disregard geometric effects of soil penetration, leading to underestimation of penetration stresses during cone tip insertion. For example, the model of (Carter et al., 1986) considers only radially applied pressures that are required to expand a cylindrical cavity in the soil and not axial insertion forces modulated by the cone shape to radial cavity expansion forces. The cone penetration model of Yu (1993) uses semi-empirical factors to account for the penetration angle and interfacial friction but assumes that penetration stresses are invariant with respect to the cone radius. Instead of considering the gradual decay of stresses during cone insertion (as seen in Fig. 4b), the penetration stresses computed using the $\mathrm{Yu}$ (1993) model remain constant, hence the resulting forces do not vary during cone tip penetration. Both alternative models strongly underestimated the penetration forces obtained in our experiments (by factors of four and two, respectively). For earthworm activity in soil, such underestimation would affect estimates of the energy requirement and related $\mathrm{C}$ consumption (or the mechanical energy requirement for root growth).

The LEFM model proposed for modeling sediment penetration by marine worms (Dorgan et al., 2007) generally overestimated penetration forces, which was much more pronounced in wet than in dry soil (Fig. 7b). This bias could be attributed to the way mechanical parameters scale to the force-displacement behavior. Because fracture toughness is linearly related to yield stress, this would require squaring the yield stress values and modifying the way insertion forces are scaled relative to the cavity expansion model. The LEFM model predicts a linear increase in insertion force with depth (with cavity width in Dorgan et al., 2011, Eq. [2]). However, experiments clearly show that this assumption is incorrect for cavity expansion in soil, as the force-displacement behavior follows a nonlinear (nearly quadric) shape until full cone insertion, when the insertion force becomes constant (in the absence of soil-shaft friction).

Table 4. Population consumption rates for a range of physical and ecological parameters. Individual values were converted from saturation degree using Fig. 10.

\begin{tabular}{l|ll|l|}
$\begin{array}{l}\text { Relative } \\
\text { saturation }\end{array}$ & Penetration rate & Population density & $\begin{array}{l}\text { Soil organic C } \\
\text { requirement }\end{array}$ \\
\hline & $\mathrm{m} \mathrm{yr}^{-1}$ & $\mathrm{no.} \mathrm{m}^{-2}$ & $\mathrm{~kg} \mathrm{~m}^{-2} \mathrm{yr}^{-1}$ \\
0.6 & 36.5 & 60 & 0.4 \\
0.8 & & 100 & 0.7 \\
& 36.5 & 60 & 0.1 \\
& & 100 & 0.2 \\
\hline
\end{tabular}


The experiments presented in this study offer new insights into the role of interfacial friction and forefront compaction during cone penetration and their dependence on cone geometry. Sharp cones $\left(15^{\circ}\right.$ semi-angle) with recessed shafts greatly reduced frictional shaft effects, suggesting that they could be used to assess mechanical soil properties in undisturbed soil. The results for the recessed-shaft, sharp cones were captured using a simple representation of cavity expansion via cone penetration models (Houlsby and Withers, 1988). In contrast, penetration forces continued to increase past full cone insertion for the recessed-shaft obtuse cones $\left(30^{\circ}\right.$ semi-angle). The difference is attributed to different patterns in the forefront soil compaction during cone penetration and subsequent soil rebound (Durban and Fleck, 1992; Yu, 1993). Sharp cones efficiently displace the soil radially (closer to an ideal cavity expansion analog), and by recessing the shaft, the effect of rebounding soil contact is reduced. For the obtuse cones, soil deformation is pronounced at the forefront of the cone, where the pushed soil accumulates at the forefront up to a critical point when soil particles move around the cone (Fig. 9a) and result in increased rebound effects. This was also evident in X-ray tomography images presented by Greacen and Sands (1980). The simplified analytical model (Ruiz et al., 2015) considers only normal forces acting on the cone face, with simple plastic deformation in the far field. Details of cone angle influences on the soil deformation and non-ideal elastic-plastic rebound are not considered.

Based on these observations and the burrowing characteristics of earthworms, we assume that recessed cone penetration captures key aspects of earthworm soil penetration. Although earthworms move through the soil with their entire body (full shaft), the kinematics during peristalsis suggest that the earthworm body probably contributes very little to the frictional forces acting on an earthworm. The various groups of muscles in the earthworm hydro-skeleton enable them to locally vary their radius and propel themselves forward with a sharp tip angle, while using radial expansion behind the tip for anchoring. The parts of the worm body that move axially at any time typically contract relative to the immobile anchoring parts. Additionally, earthworms excrete a mucus coating that may reduce friction (Gray and Lissmann, 1938). The extent of force reduction is not yet characterized, and additional studies are needed to quantify such effects.

For fine-textured soil, using cone penetration measurements (especially recessed cones with acute semi-angles of $15^{\circ}$ ) offers an attractive method for inferring the soil mechanical properties of undisturbed soils in situ, which are not possible using conventional compression tests. We observed that the cone-inferred soil strength (Table 3) agreed well with uniaxial test results for the silt loam soil. Noticeably larger values of the shear modulus $(G)$ were obtained for high water contents $\left(0.3 \mathrm{~kg} \mathrm{~kg}^{-1}\right)$. It is possible that the cone penetrometer measures $G$ more accurately than the uniaxial test due to the nature of radial deformation. The inverse determination of soil mechanical parameters was less consistent when determining them with cones possessing obtuse semi-angles $\left(30^{\circ}\right)$. They often failed to correlate with the uniaxial test. As discussed above, the large axial compaction could play a role in misrepresenting soil mechanical parameters (based on the simple model).

Energy calculations related to cone penetration provide estimates of energy requirements for soil bioturbation by earthworms (provided that the model captures the salient features of the burrowing mechanics of earthworms). According to our calculations, an earthworm would require at least $0.2 \mathrm{~g}$ of SOC to construct a burrow of 1 -m length in silt loam at $0.25 \mathrm{~kg} \mathrm{~kg}^{-1}$ water content (Fig. 10). This value is an order of magnitude higher than our previous estimate (Ruiz et al., 2015), which was based on literature values of soil mechanical properties obtained from shear tests (Cokca et al., 2004; Ghezzehei and Or, 2001) rather than compression tests. Soil strengths measured in the present study were substantially higher, leading to higher energy consumption for soil penetration and suggesting that earthworms would operate near their (hydro-skeletal) pressure limit $(\approx 250 \mathrm{kPa})$ even at the relatively high water contents considered in this study. Considering up to $8 \mathrm{~d}$ for the construction of a 1-m-long burrow (Capowiez and Belzunces, 2001) by an earthworm of $1 \mathrm{~g}$ fresh weight and consumption of $0.2 \mathrm{~g}$ SOC in the process would result in a respiration rate of $25 \mathrm{mg} \mathrm{C} \mathrm{d}^{-1}$, which falls in the same range as observed respiration rates (between 2.4 and $72 \mathrm{mg} \mathrm{C} \mathrm{d}^{-1} \mathrm{~g}^{-1}$ earthworm fresh weight [Edwards and Bohlen, 1996; Speratti and Whalen, 2008]). These values greatly exceed earthworm respiration rates at rest, which range between 0.37 and $0.48 \mathrm{mg} \mathrm{C} \mathrm{d}^{-1} \mathrm{~g}^{-1}$ fresh weight (Burges and Raw, 1967; Phillipson and Bolton, 1976). This implies that respiration related to mechanical work could account for $>98 \%$ of total earthworm respiration in some cases.

Finally, considering a population density of 100 individuals $\mathrm{m}^{-2}$ (Chan, 2001) and assuming that an individual burrows $15 \mathrm{~m}$ $\mathrm{yr}^{-1}$ on average $\left(0.125 \mathrm{~m} \mathrm{~d}^{-1}\right.$ [Capowiez and Belzunces, 2001] during five to eight active months per year [Edwards and Bohlen, 1996]), we estimate that the earthworm population would consume roughly $0.3 \mathrm{~kg} \mathrm{C} \mathrm{m}^{-2} \mathrm{yr}^{-1}$ to cover their energy costs of burrowing in a soil at $60 \%$ saturation. Considering the top 0.3 $\mathrm{m}$ of a soil with $1.5 \%$ SOC and $1500 \mathrm{~kg} \mathrm{~m}^{-3}$ bulk density (Batjes, 1996), the range of estimates of the earthworm SOC consumption rate suggest that earthworms may deplete up to $4.5 \%$ of the total SOC per year just to cover their mechanical energy requirements. Such consumption rates would deplete the soil C pool within $22 \mathrm{yr}$ if not replenished (e.g., by decaying plant tissue or manure application). Note that these rates exceed by an order of magnitude the annual $\mathrm{C}$ depletion rates of $0.05 \mathrm{~kg} \mathrm{C} \mathrm{m}^{-2}$ reported for invasive earthworm populations under field conditions by Alban and Berry (1994). Recently, Crumsey et al. (2013) reported $\mathrm{C}$ consumption rates of about $0.15 \mathrm{~kg} \mathrm{C} \mathrm{m}^{-2}$ over 8 mo for a similar population density as in our calculation (100 individuals $\mathrm{m}^{-2}$ ), which is closer to our updated estimates for mechanical energy requirements. 
Soil hydration conditions and mechanical properties strongly affect estimates of energy and $\mathrm{C}$ requirements for soil burrowing. Additionally, ecological constraints, earthworm population size, and physiological behavior play important roles in deriving such estimates of $\mathrm{C}$ consumption. In the long term, annual average $\mathrm{C}$ consumption by earthworms cannot exceed the rate of $\mathrm{C}$ input to the soil, which is some fraction of the net primary productivity (NPP). With NPP in soils supporting earthworm activity in the range of 1 to $4 \mathrm{~kg} \mathrm{C} \mathrm{m}^{-2} \mathrm{yr}^{-1}$, our estimates of mechanical energy requirements would suggest consumption of a significant proportion of SOC. However, note that our estimates are based on constant and homogeneous conditions, whereas earthworms have the possibility to modulate their activity in space and time, with the potential to substantially reduce their mechanical energy needs for burrowing.

\section{Summary and Conclusions}

The main findings of this study are summarized in the following:

1. Experimental evaluation of an analytic model for penetration-cavity expansion forces yielded close agreement between measurements and model results using cones with a size and geometry similar to earthworms and roots (millimeter scale), much better than three other, previously proposed models.

2. The simple model enables the use of cone penetration measurements for in situ estimation of soil mechanical parameters and energy costs related to root and earthworm soil bioturbation.

3. Energy requirements for typical soil earthworm communities translated to SOC consumption required to support mechanical activity (formation of new burrows) represent a non-negligible fraction of the SOC pool on the order of 3 to $10 \% \mathrm{yr}^{-1}$.

The present modeling framework probably oversimplifies the complex array of biophysical processes and constraints associated with plant root growth and earthworm ecology in soil. However, the model allows estimates of energy requirements and physical limits for the creation of different biopores in soil. This study provides a means for assessing the capacity of the SOC pool to support the levels of bioturbation necessary for soil structure generation and maintenance. However, the rapid burrowing rates of earthworms relative to the slow growth of plant roots may require a larger energy investment for the same burrow size due to rate-dependent deformation processes, which were not considered in this study. These aspects will be the focus of future studies.

\section{Symbols Used in This Study}

$\begin{array}{cl}\sigma_{\mathrm{r}} & \text { radial stress, } \mathrm{Pa} \\ \sigma_{\theta} & \text { hoop stress, } \mathrm{Pa} \\ r & \text { radius, } \mathrm{m} \\ \phi & \text { internal friction angle, rad } \\ s_{\mathrm{u}} & \text { shear soil strength, } \mathrm{Pa} \\ G & \text { shear modulus of rigidity, Pa } \\ \nu & \text { Poisson's ratio, } \mathrm{m} \mathrm{m}^{-1}\end{array}$

$\begin{array}{ll}P_{\mathrm{L}} & \text { cylindrical limit pressure, } \mathrm{Pa} \\ r_{\mathrm{b}} & \text { initial plastic radius, } \mathrm{m} \\ A_{\mathrm{c}} & \text { effective cylinder area, } \mathrm{m}^{2} \\ z & \text { penetration depth, } \mathrm{m} \\ \alpha & \text { semi-apex cone angle, rad } \\ \mu & \text { cone-soil interfacial friction coefficient } \\ F_{r} & \text { radial force, } \mathrm{N} \\ F_{z} & \text { axial force, } \mathrm{N} \\ F_{\mathrm{n}} & \text { operational cone face normal force, } \mathrm{N} \\ F_{\mathrm{f}} & \text { frictional force, } \mathrm{N} \\ F_{Z, M} & \text { measured axial force, } \mathrm{N} \\ q_{\mathrm{P}} & \text { cone penetration stress, } \mathrm{Pa} \\ F_{\mathrm{n}, \mathrm{s}} & \text { force normal to the shaft, } \mathrm{N} \\ A_{\mathrm{s}, \mathrm{s}} & \text { surface area of the shaft, } \mathrm{m}^{2} \\ l_{\mathrm{c}} & \text { cone length, } \mathrm{m} \\ F_{\mathrm{f}, \mathrm{s}} & \text { shaft frictional force, } \mathrm{N} \\ \beta & \text { proportionality coefficient, } \mathrm{m}^{1 / 2} \\ K_{\mathrm{IC}, \mathrm{EP}} & \text { elasto-plastic fracture toughness, } \mathrm{Pa} \mathrm{m}{ }^{1 / 2} \\ K_{\mathrm{IC}, \mathrm{LE}} & \text { linear elastic fracture toughness, } \mathrm{Pa} \mathrm{m}^{1 / 2} \\ E & \text { Young's modulus of elasticity, } \mathrm{Pa} \\ \sigma_{\mathrm{y}} & \text { von Mises yield stress, } \mathrm{Pa} \\ \sigma_{z} & \text { axial stress under compression, } \mathrm{Pa} \\ \varepsilon_{z} & \text { axial strain under compression, } \mathrm{Pa}\end{array}$

\section{Acknowledgments}

We gratefully acknowledge funding from the Swiss National Science Foundation-National Research Program on "Soil as a Resource"-NRP68 (SNF, Grant no. 406840143061 Biophysical processes controlling restoration of compacted soil structure-Long-term soil structure observatory and mechanistic studies) and Dr. Thomas Keller (Agroscope) for the many helpful discussions.

\section{References}

Abdalla, A., D. Hettiaratchi, and A. Reece. 1969. The mechanics of root growth in granular media. J. Agric. Eng. Res. 14:236-248. doi:10.1016/0021-8634(69)90126-7

Adamchuk, V.I., J. Hummel, M. Morgan, and S. Upadhyaya. 2004. Onthe-go soil sensors for precision agriculture. Comput. Electron. Agric. 44:71-91. doi:10.1016/j.compag.2004.03.002

Alban, D.H., and E.C. Berry. 1994. Effects of earthworm invasion on morphology, carbon, and nitrogen of a forest soil. Appl. Soil Ecol. 1:243249. doi:10.1016/0929-1393(94)90015-9

Bastardie, F., Y. Capowiez, and D. Cluzeau. 2005. 3D characterisation of earthworm burrow systems in natural soil cores collected from a 12-yearold pasture. Appl. Soil Ecol. 30:34-46. doi:10.1016/j.apsoil.2005.01.001

Batjes, N.H. 1996. Total carbon and nitrogen in the soils of the world. Eur. J. Soil Sci. 47:151-163. doi:10.1111/j.1365-2389.1996.tb01386.x

Bengough, A., and C. Mullins. 1990. Mechanical impedance to root growth: A review of experimental techniques and root growth responses. J. Soil Sci. 41:341-358. doi:10.1111/j.1365-2389.1990.tb00070.x

Bengough, A., C. Mullins, and G. Wilson. 1997. Estimating soil frictional resistance to metal probes and its relevance to the penetration of soil by roots. Eur. J. Soil Sci. 48:603-612. doi:10.1111/j.1365-2389.1997.tb00560.x

Berli, M., M. Accorsi, and D. Or. 2006. Size and shape evolution of pores in a viscoplastic matrix under compression. Int. J. Numer. Anal. Methods Geomech. 30:1259-1281. doi:10.1002/nag.529

Bishop, R., R. Hill, and N. Mott. 1945. The theory of indentation and hardness tests. Proc. Phys. Soc. 57:147-159. doi:10.1088/0959-5309/57/3/301

Booth, L.H., V. Heppelthwaite, and A. McGlinchy. 2000. The effect of environmental parameters on growth, cholinesterase activity and glutathione S-transferase activity in the earthworm (Apporectodea caliginosa). Biomarkers 5:46-55. doi:10.1080/135475000230532

Bottinelli, N., P. Jouquet, Y. Capowiez, P. Podwojewski, M. Grimaldi, and $X$. Peng. 2014. Why is the influence of soil macrofauna on soil structure only considered by soil ecologists? Soil Tillage Res. 146:1 18-124. doi:10.1016/j.still.2014.01.007 
Brown, G.G., I. Barois, and P. Lavelle. 2000. Regulation of soil organic matter dynamics and microbial activity in the drilosphere and the role of interactions with other edaphic functional domains. Eur. J. Soil Biol. 36:177-198. doi:10.1016/S1164-5563(00)01062-1

Burges, A., and R. Raw, editors. 1967. Soil biology. Academic Press, London.

Capowiez, Y., and L. Belzunces. 2001. Dynamic study of the burrowing behaviour of Aporrectodea nocturna and Allolobophora chlorotica: interactions between earthworms and spatial avoidance of burrows. Biol. Fertil. Soils 33:310-316. doi:10.1007/s003740000327

Carter, J.P., J.R. Booker, and S.K. Yeung. 1986. Cavity expansion in cohesive frictional soils. Geotechnique 36:349-358. doi:10.1680/geot.1986.36.3.349

Chan, K. 2001. An overview of some tillage impacts on earthworm population abundance and diversity: Implications for functioning in soils. Soil Tillage Res. 57:179-191. doi:10.1016/S0167-1987(00)00173-2

Cokca, E., O. Erol and F. Armangil. 2004. Effects of compaction moisture content on the shear strength of an unsaturated clay. Geotech. Geol. Eng. 22:285-297.

COMSOL. 2012. COMSOL Multiphysics user's guide, Version 4.3. COMSOL, Burlington, MA.

Crumsey, J.M., J.M. Le Moine, Y. Capowiez, M.M. Goodsitt, S.C. Larson, G.W. Kling, and K.J. Nadelhoffer. 2013. Community-specific impacts of exotic earthworm invasions on soil carbon dynamics in a sandy temperate forest. Ecology 94:2827-2837. doi:10.1890/12-1555.1

Curry, J. 1998. Factors affecting earthworm abundance in soils. In: C.A Edwards, editor, Earthworm ecology. St. Lucie Press, Boca Raton, FL. p. 37-64.

Dexter, A. 1987. Mechanics of root growth. Plant Soil 98:303-312. doi:10.1007/BF0237835

Dexter, A., G. Richard, D. Arrouays, E.A. Czyż, C. Jolivet, and O. Duval. 2008. Complexed organic matter controls soil physical properties. Geoderma 144:620-627. doi:10.1016/j.geoderma.2008.01.022

Dorgan, K.M., S.R. Arwade, and P.A. Jumars. 2007. Burrowing in marine muds by crack propagation: Kinematics and forces. J. Exp. Biol. 210:4198-4212. doi:10.1242/jeb.010371

Dorgan, K.M., S. Lefebvre, J.H. Stillman, and M. Koehl. 2011. Energetics of burrowing by the cirratulid polychaete Cirriformia moorei. J. Exp. Biol. 214:2202-2214. doi:10.1242/jeb.054700

Durban, D., and N.A. Fleck. 1992. Singular plastic fields in steady penetration of a rigid cone. J. Appl. Mech. 59:706-710. doi:10.1115/1.2894032

Edwards, C.A. and P.J. Bohlen. 1996. Biology and ecology of earthworms. Chapman and Hall, London.

Eggers, C., M. Berli, M. Accorsi, and D. Or. 2006. Deformation and permeability of aggregated soft earth materials. J. Geophys. Res. 11 1:B10204. doi:10.1029/2005JB004123

Ehlers, W. 1975. Observations on earthworm channels and infiltration on tilled and untilled loess soil. Soil Sci. 119:242-249. doi:10.1097/00010694-197503000-00010

Ghezzehei, T.A., and D. Or. 2001. Rheological properties of wet soils and clays under steady and oscillatory stresses. Soil Sci. Soc. Am. J. 65:624637. doi:10.2136/sssaj2001.653624x

Gray, J., and H. Lissmann. 1938. An apparatus for measuring the propulsive forces of the locomotory muscles of the earthworm and other animals. J. Exp. Biol. 15:518-521.

Greacen, E., and J. Oh. 1972. Physics of root growth. Nature 235:24-25.

Greacen, E.L., and R. Sands. 1980. Compaction of forest soils: A review. Soil Res. 18:163-189. doi:10.1071/SR9800163

Hallett, P.D., T. Baumgartl, J.P. Seville, R. Horn, and A.R. Dexter. 2014 Tensile strain-rate dependency of pore water pressure and failure strength of soil. Vadose Zone J. 13(5). doi:10.2136/vzj2013.06.0098

Holmstrup, M. 2001. Sensitivity of life history parameters in the earthworm Aporrectodea caliginosa to small changes in soil water potential. Soil Biol. Biochem. 33:1217-1223. doi:10.1016/S0038-0717(01)00026-8

Houlsby, G., and N. Withers. 1988. Analysis of the cone pressuremeter test in clay. Geotechnique 38:575-587. doi:10.1680/geot.1988.38.4.575

Johnson, J.B. 2003. A statistical micromechanical theory of cone penetration in granular materials. Tech Rep. ERDC/CRREL TR-03-3. US Army Corps Eng., Cold Regions Res. Eng. Lab., Hanover, NH.

Keudel, M., and S. Schrader. 1999. Axial and radial pressure exerted by earthworms of different ecological groups. Biol. Fertil. Soils 29:262-269. doi:10.1007/s00374005055

Kroener, E., M. Zarebanadkouki, A. Kaestner, and A. Carminati. 2014 Nonequilibrium water dynamics in the rhizosphere: How muci- lage affects water flow in soils. Water Resour. Res. 50:6479-6495. doi:10.1002/2013WR014756

Lavelle, P. 1988. Earthworm activities and the soil system. Biol. Fertil. Soils 6:237-251. doi:10.1007/BF00260820

Lavelle, P. S. Barot, M. Blouin, T. Decaëns, J.J. Jimenez, and P. Jouquet. 2007. Earthworms as key actors in self-organized soil systems. In: K. Cuddington et al., editors, Ecological engineers: Plants to protists. Theor. Ecol. Ser. 4. Academic Press, Burlington, MA. p. 77-106.

Ligthart, T.N., and G.J. Peek. 1997. Evolution of earthworm burrow systems after inoculation of lumbricid earthworms in a pasture in the Netherlands.Soil Biol. Biochem. 29:453-462. doi:10.1016/S0038-0717(96)00041-7

LU, N., J.W. Godt, and D.T. Wu. 2010. A closed-form equation for effective stress in unsaturated soil. Water Resour. Res. 46:W05515. doi:10.1029/2009WR008646

McKenzie, B.M., and A.R. Dexter. 1988. Radial pressures generated by the earthworm Aporrectodea rosea. Biol. Fertil. Soils 5:328-332.

Michlmayr, G., D. Cohen, and D. Or. 2013. Shear-induced force fluctuations and acoustic emissions in granular material. J. Geophys. Res. 118:6086-6098. doi:10.1002/2012JB009987

Misra, R., A. Dexter, and A. Alston. 1986. Maximum axial and radial growth pressures of plant roots. Plant Soil 95:315-326. doi:10.1007/BF02374612

Mitchell, J.K., and K. Soga. 2005. Fundamentals of soil behavior. 3rd ed. John Wiley \& Sons, New York.

Phillipson, J., and P. Bolton. 1976. The respiratory metabolism of selected Lumbricidae. Oecologia 22:135-152. doi:10.1007/BF00344713

Ruiz, S., D. Or, and S. Schymanski. 2015. Soil penetration by earthworms and plant roots: Mechanical energetics of bioturbation of compacted soils. PLOS ONE 10(6):e0128914. doi:10.1371/journal.pone.0128914

Salgado, R., and M. Prezzi. 2007. Computation of cavity expansion pressure and penetration resistance in sands. Int. J. Geomech. 7:251-265. doi:10.1061/(ASCE) 1532-3641 (2007)7:4(251)

Speratti, A.B., and J.K. Whalen. 2008. Carbon dioxide and nitrous oxide fluxes from soil as influenced by anecic and endogeic earthworms. Appl. Soil Ecol. 38:27-33. doi:10.1016/j.apsoil.2007.08.009

Stolzy, L., and K. Barley. 1968. Mechanical resistance encountered by roots entering compact soils. Soil Sci. 105:297-301. doi:10.1097/00010694-196805000-00003

Tolooiyan, A., and K. Gavin. 2011. Modelling the cone penetration test in sand using cavity expansion and arbitrary Lagrangian Eulerian finite element methods. Comput. Geotech. 38:482-490. doi:10.1016/j.compgeo.2011.02.012

Unger,P.W., andT.C.Kaspar. 1994.Soilcompactionandrootgrowth:Areview. Agron. J. 86:759-766. doi:10.2134/agronj1994.00021962008600050004x

von Mises, R. 1913. Mechanics of solid bodies in the plastically-deformable state. (In German.) Nachr. Ges. Wiss. Goettingen, Math.-Phys. KI. $1: 582-592$

Wang, J.-J., J.-G. Zhu, C.F. Chiu, and H. Zhang. 2007. Experimental study on fracture toughness and tensile strength of a clay. Eng. Geol. 94:6575. doi:10.1016/j.enggeo.2007.06.005

Watts, C., P. Hallett, and A. Dexter. 1999. Effects of mechanical stresses and strains on soil respiration. In: J. Berthelin et al., editors, Effect of mineral-organic-microorganism interactions on soil and freshwater environments. Springer Science + Business Media, Berlin. p. 305-316.

Whalley, W., P. Leeds-Harrison, L. Clark, and D. Gowing. 2005. Use of effective stress to predict the penetrometer resistance of unsaturated agricultural soils. Soil Tillage Res. 84:18-27. doi:10.1016/j.still.2004.08.003

Whalley, W., J. To, B. Kay, and A. Whitmore. 2007. Prediction of the penetrometer resistance of soils with models with few parameters. Geoderma 137:370-377. doi:10.1016/j.geoderma.2006.08.029

Whiteley, G., W. Utomo, and A. Dexter. 1981. A comparison of penetrometer pressures and the pressures exerted by roots. Plant Soil 61:351-364. doi:10.1007/BF02182016

Wraith, J.M., and D. Or. 1998. Nonlinear parameter estimation using spreadsheet software. J. Nat. Resour. Life Sci. Educ. 27:13-19.

Yoshida, S., and P. Hallett. 2008. Impact of hydraulic suction history on crack growth mechanics in soil. Water Resour. Res. 44:W00C01. doi:10.1029/2007WR006055

Yu, H. 1993. Discussion: "Singular Plastic Fields in Steady Penetration of a Rigid Cone" (Durban, D., and Flek, N.A., 1992, ASME J. Appl Mech., 59 p. 706-710). J. Appl. Mech. 60:1061-1062. doi:10.1115/1.290098

Yu, H., and J. Mitchell. 1998. Analysis of cone resistance: Review of methods. J. Geotech. Geoenviron. Eng. 124:140-149. doi:10.1061/(ASCE) 1090-0241(1998)124:2(140) 